\title{
Knockdown of long non-coding RNA SOX2OT downregulates SOX2 to improve hippocampal neurogenesis and cognitive function in a mouse model of sepsis- associated encephalopathy
}

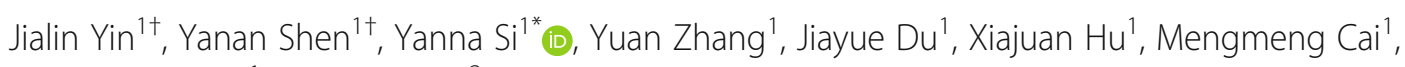
Hongguang Bao ${ }^{1}$ and Yan Xing ${ }^{2}$

\begin{abstract}
Background: Aberrant hippocampal neurogenesis is an important pathological feature of sepsis-associated encephalopathy. In the current study, we examined the potential role of the long noncoding RNA (IncRNA) sexdetermining region Y-box 2 (SOX2) overlapping transcript (SOX2OT), a known regulator of adult neurogenesis in sepsis-induced deficits in hippocampal neurogenesis and cognitive function.

Methods: Sepsis was induced in adult C57BL/6 J male mice by cecal ligation and perforation (CLP) surgery. Randomly selected CLP mice were transfected with short interfering RNAs (siRNAs) against SOX2OT or SOX2, or with scrambled control siRNA. Cognitive behavior was tested 8-12 days post-surgery using a Morris water maze. Western blotting and RT-qPCR were used to determine expression of SOX2, Ki67, doublecortin (DCX), nestin, brain lipid-binding protein, and glial fibrillary acidic protein (GFAP) in the hippocampus. The number of bromodeoxyuridine $(\mathrm{BrdU})^{+} / \mathrm{DCX}^{+}$cells, $\mathrm{BrdU}^{+} /$neuronal nuclei $(\mathrm{NeuN})^{+}$neurons, and $\mathrm{BrdU}^{+} / \mathrm{GFAP}^{+}$glial cells in the dentate gyrus were assessed by immunofluorescence.

Results: CLP mice showed progressive increases in SOX2OT and SOX2 mRNA levels on days 3, 7, and 14 after CLP surgery, accompanied by impaired cognitive function. Sepsis led to decrease in all neuronal markers in the hippocampus, except GFAP. Immunofluorescence confirmed the decreased numbers of $\mathrm{BrdU}^{+} / \mathrm{DCX}^{+}$cells and $\mathrm{BrdU}^{+} / \mathrm{NeuN}^{+}$neurons, and increased numbers of $\mathrm{BrdU}^{+} / \mathrm{GFAP}^{+}$cells. SOX2OT knockdown partially inhibited the effects of CLP on levels of SOX2 and neuronal markers, neuronal populations in the hippocampus, and cognitive function. SOX2 deficiency recapitulated the effects of SOX2OT knockdown.

(Continued on next page)
\end{abstract}

\footnotetext{
* Correspondence: siyanna@163.com

${ }^{\dagger}$ Jialin Yin and Yanan Shen contributed equally to this work.

'Department of Anesthesiology, Nanjing First Hospital, Nanjing Medical University, Nanjing 210006, People's Republic of China

Full list of author information is available at the end of the article
}

C C The Author(s). 2020 Open Access This article is licensed under a Creative Commons Attribution 4.0 International License, which permits use, sharing, adaptation, distribution and reproduction in any medium or format, as long as you give appropriate credit to the original author(s) and the source, provide a link to the Creative Commons licence, and indicate if changes were made. The images or other third party material in this article are included in the article's Creative Commons licence, unless indicated otherwise in a credit line to the material. If material is not included in the article's Creative Commons licence and your intended use is not permitted by statutory regulation or exceeds the permitted use, you will need to obtain permission directly from the copyright holder. To view a copy of this licence, visit http://creativecommons.org/licenses/by/4.0/ The Creative Commons Public Domain Dedication waiver (http://creativecommons.org/publicdomain/zero/1.0/) applies to the data made available in this article, unless otherwise stated in a credit line to the data. 


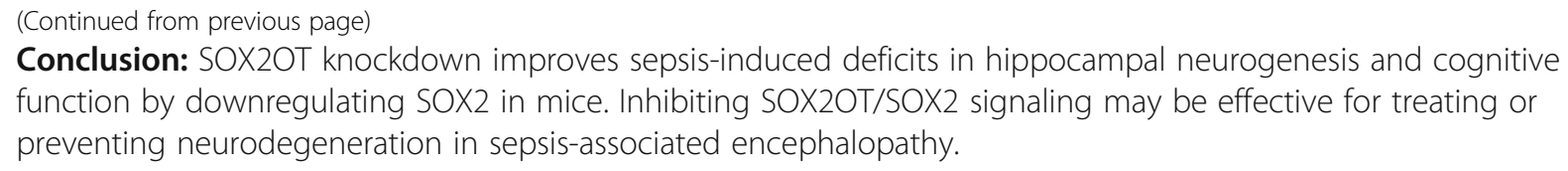

Keywords: Sepsis-associated encephalopathy, Cognitive dysfunction, Hippocampal neurogenesis, SOX2OT, SOX2

\section{Background}

Sepsis is a primary clinical challenge and often results in multiple organ dysfunction. Sepsis and its complications are the most frequent cause of high morbidity and mortality in the intensive care unit [1,2], although recent medical advances have substantially enhanced survival rates. Sepsis-associated encephalopathy is a severe complication with incidence of 9-71\%. Patients with sepsisassociated encephalopathy show various degrees of cognitive dysfunction, ranging from impaired consciousness to delirium that can persist for months to years after hospital discharge. These patients often require longterm medical interventions in order to regain function [2]. These adverse neurobehavioral consequences are often associated with reduced quality of life, poor prognosis, and increased morbidity and mortality [3].

The cognitive impairment in sepsis-associated encephalopathy is associated with dysfunctional hippocampal neurogenesis [4]. Neural stem cells persist into adulthood and maintain the production, survival, migration, and recruitment of new neurons $[5,6]$, but studies in a mouse model of sepsis induced by lipopolysaccharide indicate decreased proliferation and survival of new neurons, and dysfunction differentiation in the dentate gyrus [4, 7]. These animals also show decreased synaptic plasticity, leading to learning and memory deficits [4, 7]. Brain neurogenesis has been shown to be regulated by long noncoding RNAs (lncRNAs), a class of transcripts longer than 200 nucleotides [8-10]. Therefore, treatments based on lncRNA may be effective against neurodegeneration induced by sepsis-associated encephalopathy [11].

Sex-determining region Y-box 2 (SOX2) overlapping transcript (SOX2OT), a highly conserved lncRNA among vertebrates [12], has been linked to cognitive impairment in a mouse model of Alzheimer's disease [13]. SOX2OT is expressed in zones of active neurogenesis in adult mouse brain [14]. SOX2OT is also highly expressed in areas of dynamic proliferation and differentiation of adult neural stem cells [12]. SOX2 arises from a single exon within one of the SOX2OT introns and the two transcripts are frequently detected together, perhaps due to their overlapping transcriptional orientation $[12,13,15]$. An in vitro study involving neuronal stem and progenitor cells isolated from the subventricular zone of adult mice showed that SOX2OT and SOX2 are upregulated in the early stages of neuronal proliferation; then, their levels progressively decrease as cells differentiate [12]. In fact, SOX2OT downregulates SOX2 in neural progenitor cells and thereby represses neural progenitor proliferation and promotes cortical neurogenesis in the developing mouse brain [15].

Therefore, we sought to examine here whether IncRNA SOX2OT may be involved in sepsis-induced hippocampal neurogenesis and cognitive dysfunction in a mouse model. We also asked whether knocking down SOX2OT may ameliorate these sepsis-induced effects by downregulating SOX2.

\section{Material and methods \\ Animals}

All animal experimental protocols were approved by the Institutional Animal Care and Use Committee at Nanjing Medical University (protocol reference number 2017-142). Adult male C57BL/6 J mice (6-8-week old, 25-31 g, Experimental Animal Center at Nanjing First Hospital) were housed in a temperature- and humiditycontrolled facility on a 12-h light-dark cycle with free access to food and water. Only male mice were used in the experiments to minimize the heterogeneity due to sex differences in the pathology of encephalopathy [16].

\section{Experimental design}

The mouse sepsis model was established using cecal ligation and perforation (CLP) surgery as previously described [16]. Mice were randomly assigned to the following groups $(n=15 /$ group$)$ : naïve, sham operated, or CLP. CLP mice were further treated with one of the following ( $n=16 /$ group): short interfering RNA (siRNA) against SOX2OT, siRNA against SOX2, or scrambled control siRNA 3d before CLP. After CLP surgery, mice were subjected to the Morris water maze trial for 5 days starting on day 8 , and a fear conditioning test was performed on day 13 (Fig. 1). Mice were sacrificed, and the hippocampus was removed for RT-PCR, western blotting, and immunohistochemistry.

\section{CLP surgery}

The mouse sepsis model was established as previously described [16] with some modifications. Briefly, animals were anesthetized using intraperitoneal ketamine $(80$ $\mathrm{mg} / \mathrm{kg}$ ) and xylazine $(5 \mathrm{mg} / \mathrm{kg}$ ). After disinfection, a 2-3$\mathrm{cm}$ incision was made lengthwise below the xiphoid to 

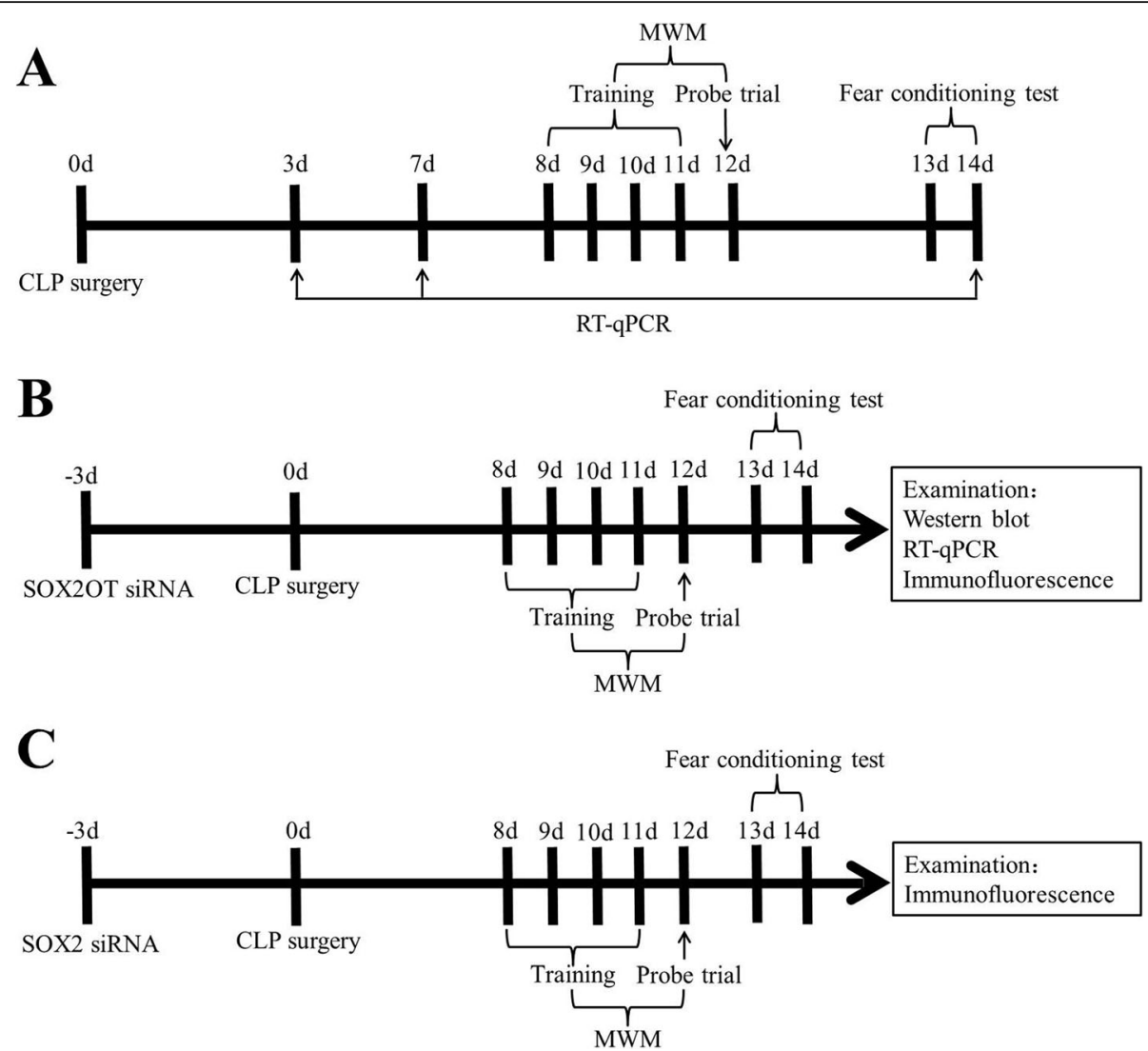

Fig. 1 Schematic illustration of the experimental design. a Timeline for naive, sham-operated, or CLP-operated mice. b Timeline for mice injected with scrambled control siRNA or SOX2OT siRNA. c Timeline for mice injected with scrambled control siRNA or SOX2 siRNA. Abbreviations: CLP, cecal ligation and perforation; d, day; MWM, Morris water maze; RT-qPCR, reverse transcription-quantitative polymerase chain reaction; siRNA, short interfering RNA; SOX2, sex-determining region Y-box 2; SOX2OT, SOX2 overlapping transcript

expose the abdominal cavity. The cecum was isolated and ligated at half the distance between distal pole and the base of the cecum, and punctured twice with a 22gauge needle (Fig. 2a). Fecal contents were gently extruded into the peritoneal cavity. Then, the cecum was carefully placed back into the abdominal cavity, and the abdomen was sutured. For sham-operated animals, the abdominal cavity was opened to expose the cecum without ligation or perforation. After surgery, $1 \mathrm{ml}$ of sterile saline prewarmed to $37^{\circ} \mathrm{C}$ was given intraperitoneally for rehydration. Animals were returned to their cages with a warm cotton pad and free access to food and water. Naïve mice did not undergo laparotomy.

\section{Bromodeoxyuridine labeling}

Bromodeoxyuridine (BrdU) is an S-phase marker of proliferating cells. To identify newly synthesized DNA after CLP surgery, animals received BrdU (50 mg/kg; Sigma, St. Louis, MO, USA) via intraperitoneal injection twice daily at $8 \mathrm{~h}$ intervals for seven consecutive days before CLP.

\section{SOX2OT and SOX2 knockdown in vivo}

SOX2OT and SOX2 were knocked down using siRNA with the following sequence: 5'-CAG CAG AGA AAT GAT ATC TAG ACC A-3' for SOX2OT (scrambled control sequence: 5'-GAC CGA TAA CGA AAG CAC AAA TTG T-3') and 5'-GCG GCG ACC GGC GGC AAC CAG AAG A-3' for SOX2 (scrambled control: 5' GAG AGC ACC GGG ACG CCG AGA CAG C-3'). The siRNAs were designed and synthesized by GenePharma (Shanghai, China). RNAs were transfected using Entranster ${ }^{\mathrm{TM}}$ in vivo transfection reagent (Engreen Biosystem, Beijing, China). The Entranster ${ }^{\mathrm{TM}}$-in-vivo-siRNA mixture was performed according to the manufacturer's instructions as previously described [17]. Briefly, $5 \mu \mathrm{g}$ of siRNA was dissolved in $5 \mu \mathrm{L}$ RNase-free water, then gently mixed with $5 \mu \mathrm{L}$ of in vivo transfection reagent. The mixture was kept at room temperature for $15 \mathrm{~min}$, then injected intracerebroventricularly (i.c.v.) using a stereotaxic apparatus as previously described [18]. The stereotaxic coordinates were $1.0 \mathrm{~mm}$ lateral and $0.5 \mathrm{~mm}$ posterior to the bregma over the left hemisphere, and $2.5 \mathrm{~mm}$ below the dural surface (Fig. 2b/c). SOX2OT or 


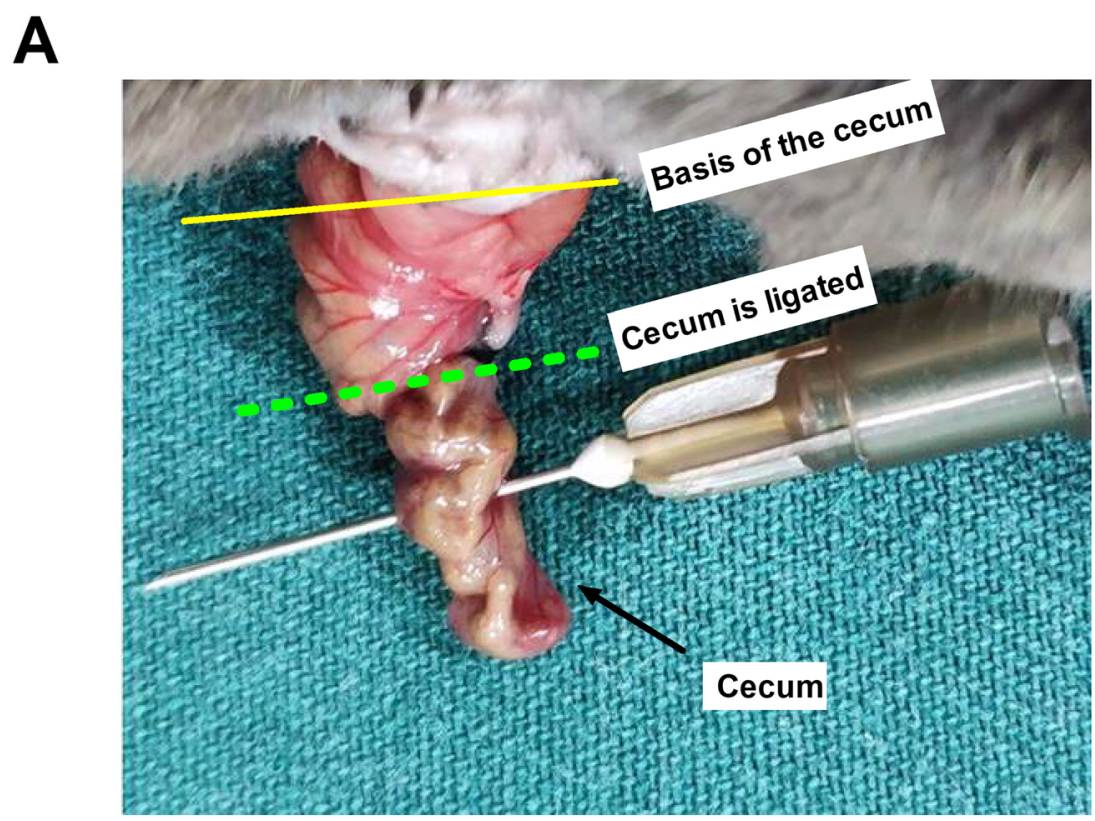

B

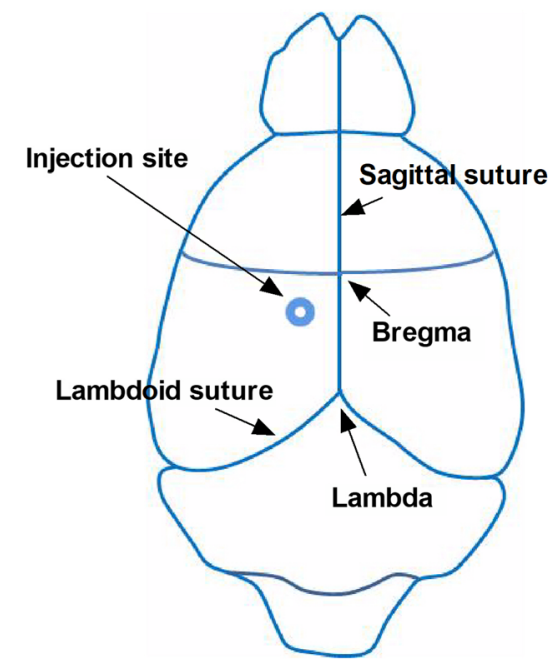

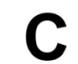

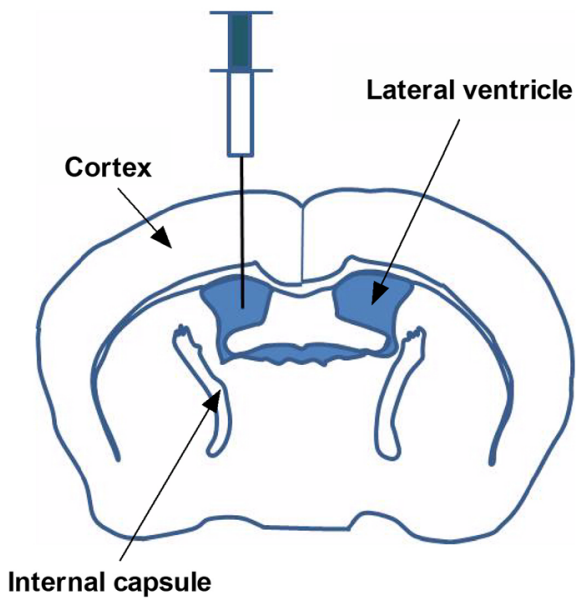

Fig. 2 A schematic illustration of CLP procedure and i.c.V. injection. a CLP procedure. The basis of the cecum is indicated by the yellow line. The cecum is ligated (indicated by dotted green line) at half the distance between distal pole and the base of the cecum. $\mathbf{b}$ Injection site of the mouse lateral ventricle. The injection site is at $1.0 \mathrm{~mm}$ lateral and $0.5 \mathrm{~mm}$ posterior to the bregma over the left hemisphere. c A $27 \mathrm{G}$ needle with a $10-\mu l$ syringe is used for the injection into the lateral ventricle $2.5-\mathrm{mm}$ deep, perpendicular to the skull surface. Abbreviations: CLP, cecal ligation and perforation; i.c.v., intracerebroventricular

SOX2 knockdown was verified using RT-PCR or Western blot.

\section{Morris water maze}

A standard 5-day Morris water maze test was performed by a researcher blinded to treatment groups [19]. The water maze consisted of a round, painted pool with a diameter of $100 \mathrm{~cm}$ and height of $40 \mathrm{~cm}$. The pool was filled with opaque water to a depth of $28 \mathrm{~cm}$ and maintained at $23 \pm 1{ }^{\circ} \mathrm{C}$. The initial 4 days included spatial acquisition training and testing sessions, which included four sessions per day at an inter-session interval of 20 min. The maximum length of the sessions was $60 \mathrm{~s}$. Animals were trained to escape by swimming onto a hidden platform at $0.5 \mathrm{~cm}$ beneath the water surface in the original target quadrant. Animals that failed to locate the platform within $60 \mathrm{~s}$ were manually guided to the platform. Mice were allowed to stay on the platform for $20 \mathrm{~s}$ before being removed. Swimming speed and escape latency were analyzed using a motion detection software 
(Actimetrics Software, Evanston, IL, USA). The escape latency from all four sessions was averaged to calculate the escape latency for each day. On the fifth day, the platform was removed to allow for probe testing. During the 60-s session, the number of crossings over the target quadrant and the total time spent in that quadrant were recorded.

\section{Fear conditioning test}

A fear conditioning testing was conducted the day after the Morris water maze experiments were completed [20]. All mice were placed in a $70 \%$ ethanol-wiped chamber with a floor of stainless-steel bars. This chamber was designed to allow sound stimulation for the training of conditioned reflexes, as well as electrical stimulation on the feet using a constant-current generator. Mice were allowed to explore and habituate in the training environment for $3 \mathrm{~min}$. Then, they were stimulated with a monofrequency sound for $30 \mathrm{~s}(1 \mathrm{kHz}, 80$ $\mathrm{dB}$ ), and during the last $2 \mathrm{~s}$ of this sound, a foot shock $(1 \mathrm{~mA})$ was delivered. After a 30-s pause, this pairing of sound and shock was delivered a second time. After 24 $\mathrm{h}$, as a test of contextual memory, mice were allowed to enter the original chamber without any stimulation to monitor freezing behavior, defined as the absence of any movement other than that required for respiration for more than $3 \mathrm{~s}$. Then, $2 \mathrm{~h}$ later, a cued fear conditioning test was conducted in which the animals were placed in the chamber and subjected to the monofrequency sound for $3 \mathrm{~min}$ without foot shock, and freezing behavior was monitored and recorded.

\section{Western blotting}

Hippocampal tissues were homogenized and centrifuged at $13,000 \mathrm{~g}$ at $4{ }^{\circ} \mathrm{C}$ for $10 \mathrm{~min}$. Proteins in the supernatant were separated by sodium dodecyl sulfate-polyacrylamide gel electrophoresis (SDS-PAGE). Proteins were then transferred onto a nitrocellulose membrane (Hybond-ECL, Amersham Biosciences, Little Chalfont, UK). Membranes were blocked and incubated overnight at $4{ }^{\circ} \mathrm{C}$ with primary antibodies against octamer-binding transcription factor 4 (OCT4; 1:200), doublecortin (DCX; 1:1000), or $\beta$-actin (1:200) (all from Santa Cruz Biotechnology, Santa Cruz, CA, USA); against SOX2 (1: 200), Ki67 (1:1000), nestin (1:1000), or brain lipidbinding protein (BLBP; 1:800) (all from Abcam, Cambridge, MA, USA); or against glial fibrillary acidic protein (GFAP; 1:1000; EMD Millipore, Billerica, MA, USA). After thorough washing, blots were incubated with secondary antibodies (Sigma-Aldrich, St. Louis, MO, USA) conjugated with horseradish peroxidase. Protein bands were detected using enhanced chemiluminescence (Amersham Biosciences) and quantitated using the Quantity One software (Bio-Rad Laboratories,
Hercules, CA, USA). Band intensities were normalized to $\beta$-actin.

\section{Reverse transcription-quantitative polymerase chain reaction analysis}

Total RNA was extracted from hippocampal tissue using Trizol reagent (Invitrogen, Carlsbad, CA, USA), then used as template for single-strand cDNA synthesis in the AMV Reverse Transcriptase Kit (Promega, Madison, WI, USA). Quantitative reverse transcription-quantitative polymerase chain reaction (RT-PCR) was performed using SYBR Green I dye detection (Takara Bio, Kusatsu, Shiga, Japan) on a real-time detection system (Bio-Rad). The PCR conditions included an initial step at $95^{\circ} \mathrm{C}$ for $3 \mathrm{~min}$, followed by 30 cycles at $95^{\circ} \mathrm{C}$ for $1 \mathrm{~min}, 56^{\circ} \mathrm{C}$ for $40 \mathrm{~s}$, and $72^{\circ} \mathrm{C}$ for $1 \mathrm{~min}$. Melting curves were created to ensure that nonspecific products were not amplified. GAPDH was used as an internal control. Relative mRNA expression of the target gene was performed by the $2^{-\triangle \Delta C T}$ method. Primers for RT-qPCR are shown in Table 1 (Genepharma, Shanghai, China).

\section{Immunofluorescence}

Animals were perfused through the left ventricle with phosphate-buffered saline followed by $4 \%$ paraformaldehyde. After perfusion, the brain was removed, post-fixed in $4 \%$ paraformaldehyde at room temperature for $2 \mathrm{~h}$, and then successively dehydrated in $20 \%$ and $30 \%$ sucrose solutions at $4{ }^{\circ} \mathrm{C}$. Brain sections $(4-\mu \mathrm{m}$ thick) were cut in a cryostat and processed for immunofluorescence. The sections were blocked with $8 \%$ goat serum for $2 \mathrm{~h}$ at room temperature, then incubated overnight at $4{ }^{\circ} \mathrm{C}$ with primary antibodies against BrdU (1:200; Abcam), DCX (1:500; Abcam), glial fibrillary acidic protein (GFAP) (1: 100; Abcam), and neuronal nuclei (NeuN) (1:400, Cell Signaling Technology, Beverly, MA, USA). The second antibody was anti-mouse or anti-rabbit IgG (1:1000; Cell Signaling Technology) conjugated with Alexa Fluor ${ }^{\circ} 488$ and Alexa Fluor ${ }^{\circ}$ 594. The sections were counterstained

Table 1 Primer sequences for RT-qPCR

\begin{tabular}{lll}
\hline Primer & & Primer Sequence(5'-3') \\
\hline SOX2OT & F & ACG GGC ACA CAT CAA GCA TA \\
SOX2 & R & AGC CTC AGC CCC CTAT ACA A \\
& F & GGG CTC TGT GGT CAA GTC CG \\
OCT4 & R & CGC TCT GGT AGT GCT GGG C \\
& F & CAA GTT GGC GTG GAG ACT TTG C \\
GAPDH & R & CCC CAA GGT GAT CCT CTT CTG C \\
& F & TGA GGC CGG TGC TGA GTA TGT CG, \\
& R & CCA CAG TCT TCT GGG TGG CAG TG \\
\hline
\end{tabular}

$F$ forward, GAPDH glyceraldehyde 3-phosphate dehydrogenase, OCT4 octamerbinding transcription factor $4, R$ reverse, SOX2OT SOX2 overlapping transcript, SOX2 sex-determining region $Y$-box 2 
A

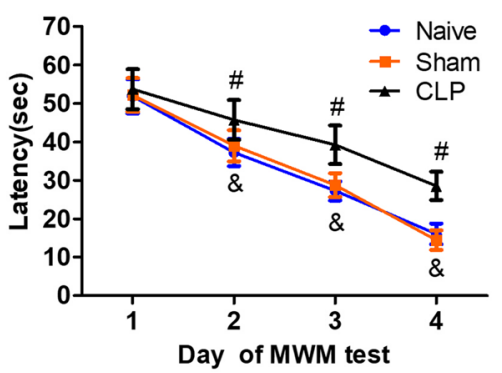

C

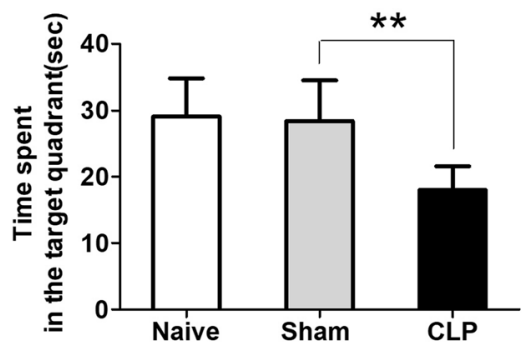

E

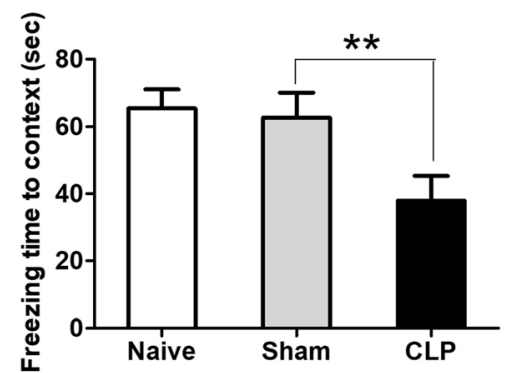

G

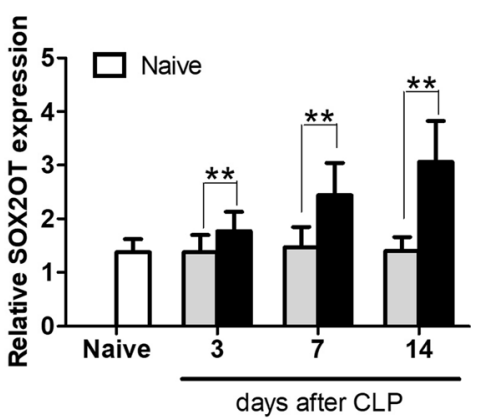

B

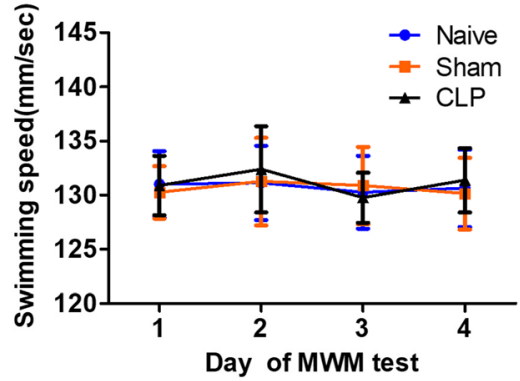

D

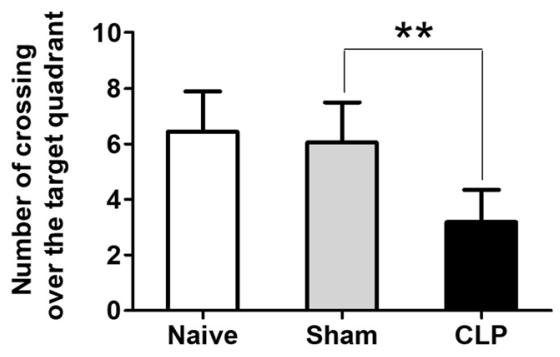

$\mathbf{F}$

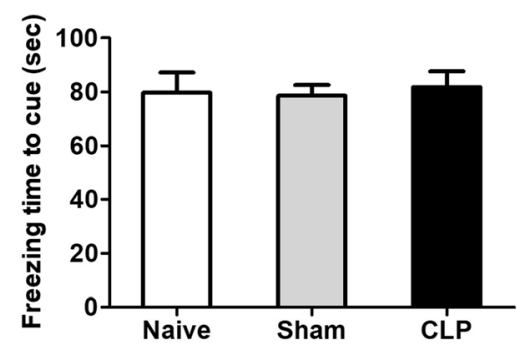

H

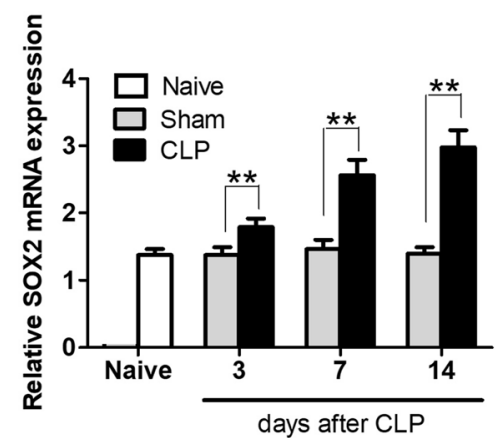

Fig. 3 Cognitive impairment and SOX2OT and SOX2 upregulation in a mouse model of sepsis-associated encephalopathy. a Escape latency time, b swimming speed, $\mathbf{c}$ time spent in the target quadrant, and $\mathbf{d}$ number of crossings over the target quadrant in the Morris water maze. e Freezing time in context and $\mathbf{f}$ freezing time in response to a cue in the fear conditioning test ( $n=15 / \mathrm{group}$ ). Relative levels of $\mathbf{g}$ SOX2OT and $\mathbf{h}$ SOX2 mRNAs were measured by RT-qPCR on days 3, 7, and 14 after sham or CLP surgery $\left(n=5 /\right.$ group). ${ }^{\&} p<0.05$ vs. day 1 of Morris water maze test; ${ }^{*} p<0.05$ vs. Sham; ${ }^{* *} p<0.05$. Abbreviations: CLP, cecal ligation and perforation; MWM, Morris water maze; SOX2, sex-determining region Ybox 2; SOX2OT, SOX2 overlapping transcript 
with 4,6-diamidino-2-phenylindole (DAPI) for $10 \mathrm{~min}$ at room temperature, and observed and imaged under an Olympus BX43 confocal microscope (Olympus, Tokyo, Japan).

\section{Statistical analysis}

Statistical analysis was performed using the Statistical Package for Social Sciences 18.0 (IBM, Chicago, IL, USA). Data are presented as mean \pm standard deviation (SD). Data from multiple groups were compared using one-way analysis of variance (ANOVA), followed by post hoc Tukey test. Data from SOX2OT and SOX2 expression patterns, and training sessions were analyzed by two-way repeated-measures ANOVA, adjusted by the Bonferroni test for main effects. Differences were considered significant when $P<0.05$.

\section{Results}

\section{Cognitive impairment and upregulation of SOX2OT and} SOX2 in sepsis-associated encephalopathy

In the Morris water maze, escape latency progressively decreased over the first 4 days of training in all groups (Fig. 3a). The CLP group had longer escape latencies than the sham group on days 2-4. There was no difference in swimming speed among groups (Fig. 3b), suggesting no motor dysfunction in any mice. Compared to the sham-operated group, the CLP group spent a shorter amount of time and had fewer crossings in the target quadrant on the test day (Fig. 3c and d). These results suggested that CLP mice had learning and memory deficits.

CLP mice exhibited shorter freezing time than sham mice in the contextual fear conditioning test (Fig. 3e). These results suggest that CLP mice displayed an environment-dependent impairment of the fear conditioning response. However, CLP and sham mice showed similar freezing time in the hippocampal-independent cued fear conditioning test (Fig. 3f), suggesting that the impairment was only in the hippocampus.

CLP mice showed progressively higher levels of SOX2OT transcript (Fig. 3g) and SOX2 transcript (Fig. 3h) than sham mice on days 3,7 , and 14 after CLP surgery.

\section{SOX2OT knockdown ameliorated sepsis-induced cognitive dysfunction in mice with sepsis-associated encephalopathy}

Since CLP mice had impaired cognitive function and upregulated SOX2OT IncRNA, which is known to regulate adult neurogenesis, we knocked down SOX2OT in vivo in order to examine whether this would mitigate the effects of CLP. In the Morris water maze, all CLP groups had longer escape latencies than the sham group on days
A

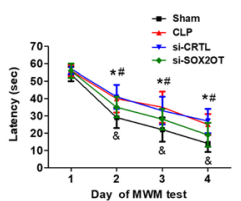

C

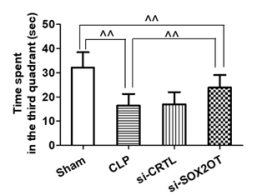

F

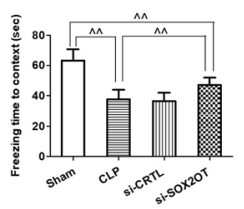

B

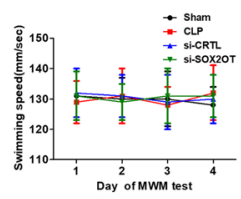

D

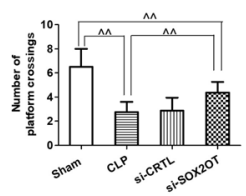

G

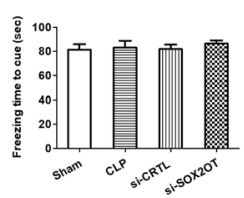

E

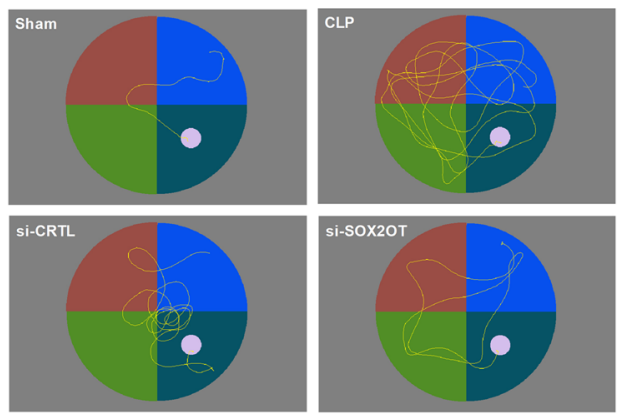

Fig. 4 SOX2OT knockdown attenuated sepsis-induced cognitive dysfunction in mice with sepsis-associated encephalopathy. a Escape latency, b swimming speed, $\mathbf{c}$ time spent in the target quadrant, $\mathbf{d}$ number of times mice crossing the target quadrant, and e representative swim paths on the test day in the Morris water maze. The white circle indicates the location of the training platform, which was removed during the test. $\mathbf{f}$ Freezing time in context and $\mathbf{g}$ freezing time in response to a cue in the fear conditioning test $\left(n=16 /\right.$ group). ${ }^{\&} p<0.05$ vs. day 1 of Morris water maze test; ${ }^{*} p<0.05$ vs. Sham; ${ }^{\#} p<0.05$ vs. CLP; $\wedge \wedge p<0.01$. Abbreviations: CLP, cecal ligation and perforation; si-CRTL, scrambled control siRNA; si-SOX2OT, SOX2OT siRNA 
2-4, regardless of SOX2OT levels, but CLP mice transfected with SOX2OT siRNA had shorter escape latencies than mice with CLP alone (Fig. 4a), suggesting that SOX2OT knockdown improved learning and memory in sepsis mice. There was no difference in swimming speed between groups (Fig. 4b). Compared to sham animals, CLP mice spent less time in the target quadrant and had fewer crossings in the target quadrant on the test day (Fig. 4c-e). SOX2OT knockdown in CLP mice prolonged time in the target quadrant and led to more crossings. No significant differences were observed between CLP mice transfected with scrambled siRNA and non-transfected CLP mice.

All CLP mice had shorter freezing time in the contextual fear conditioning test than sham mice (Fig. 4f), and SOX2OT knockdown prolonged freezing time in CLP animals. These results suggest that SOX2OT knockdown protected against environment-dependent impairment of the fear conditioning response. In contrast, the groups showed no difference in freezing time in the hippocampal-independent cued fear conditioning test (Fig. 4g).

\section{SOX2OT knockdown partially restored cell proliferation} and survival of mature neurons while reducing glial differentiation in the hippocampus of mice with sepsisassociated encephalopathy

CLP mice had fewer $\mathrm{BrdU}^{+} / \mathrm{DCX}^{+}$cells and $\mathrm{BrdU}^{+} /$ $\mathrm{NeuN}^{+}$neurons but more $\mathrm{BrdU}^{+} / \mathrm{GFAP}^{+}$glial cells in the dentate gyrus of the hippocampus than sham controls (Fig. 5). These effects of CLP were significantly inhibited by SOX2OT knockdown, although the differences remained significant between knockdown CLP animals and sham or CLP animals.

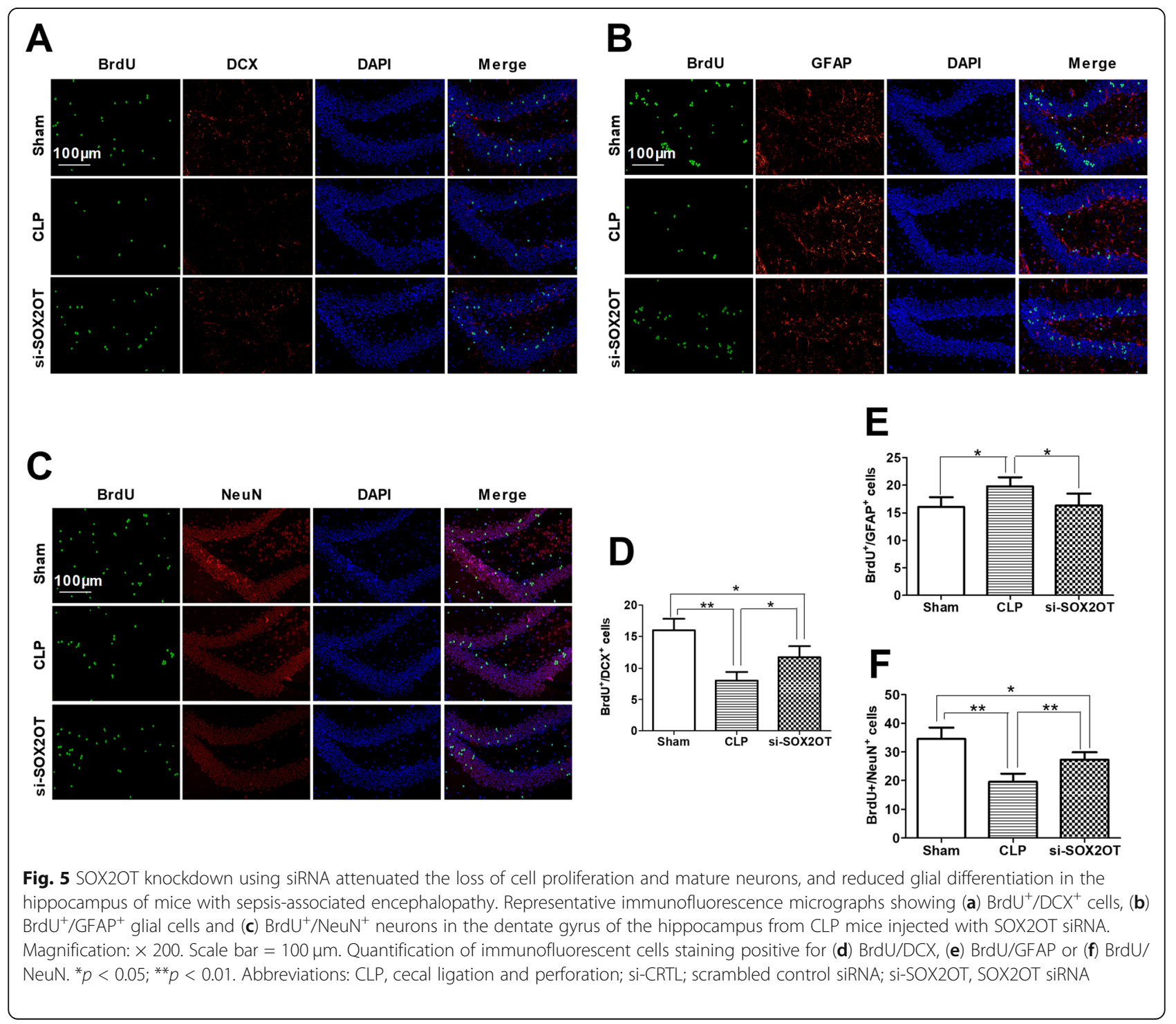




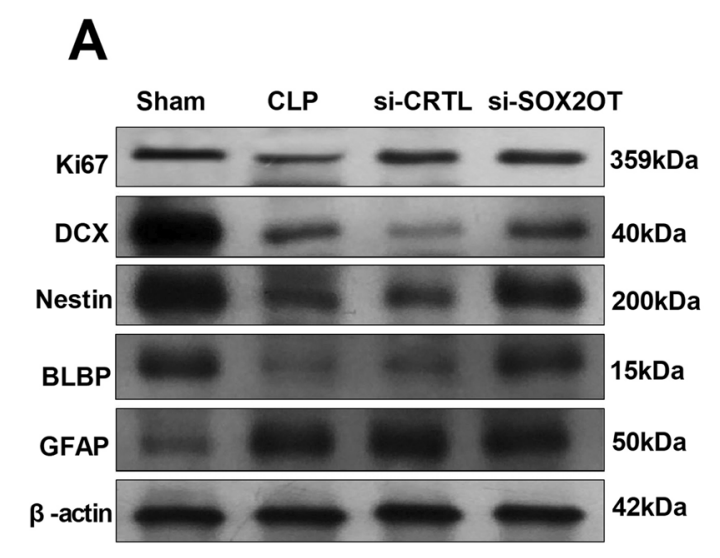

\section{B}

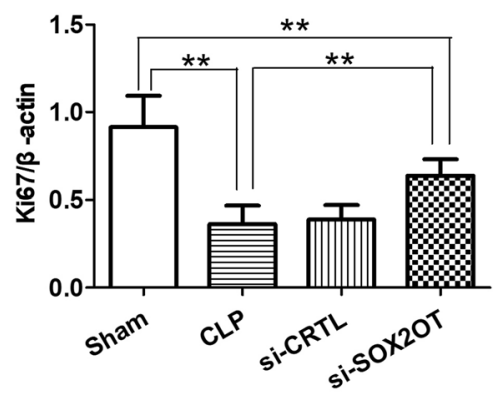

\section{C}

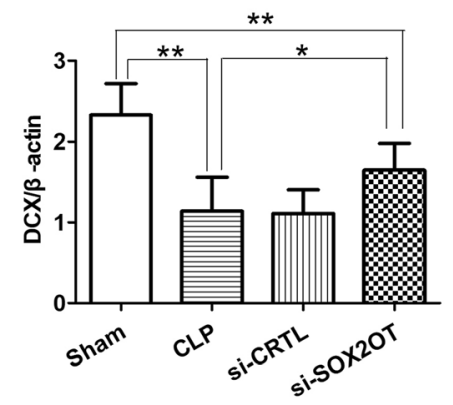

D

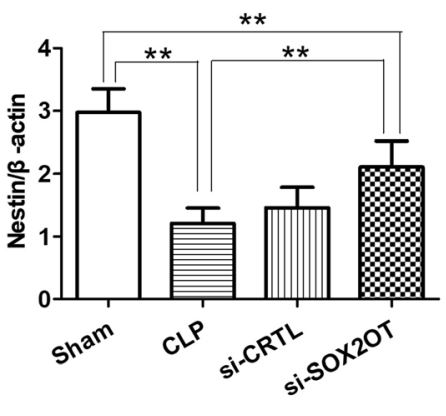

$\mathbf{E}$

$\mathbf{F}$
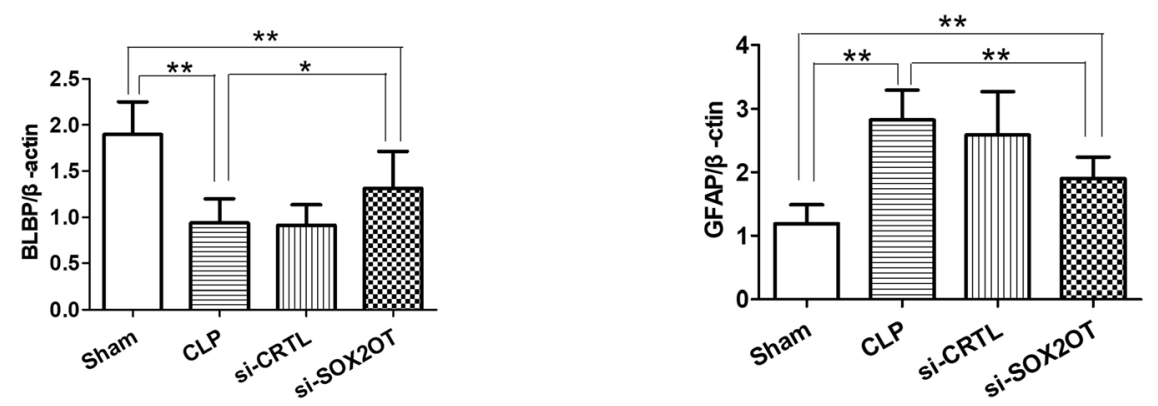

Fig. 6 SOX2OT knockdown attenuated changes in neuronal marker levels in the hippocampus of mice with sepsis-associated encephalopathy. a Representative images showing protein bands of Ki67, DCX, Nestin, BLBP, and GFAP from CLP mice injected with SOX2OT siRNA or scrambled control. Densitometry-based protein quantitation of b Ki67, c DCX, d Nestin, e BLBP, and $\mathbf{f}$ GFAP. $\beta$-actin was used as an internal control ( $n=8 /$ group). ${ }^{*} p<0.05 ;{ }^{* *} p<0.01$. Abbreviations: CLP, cecal ligation and perforation; si-CRTL; scrambled control siRNA; si-SOX2OT, SOX2OT siRNA

SOX2OT knockdown attenuated changes in the hippocampal neuronal markers in mice with sepsisassociated encephalopathy

CLP mice, with or without control siRNA, had significantly decreased protein expression of neuronal markers Ki67 (Fig. 6b), DCX (Fig. 6c), Nestin (Fig. 6d), and BLBP (Fig. 6e) in the hippocampus than the sham controls. Conversely, CLP animals showed 3-fold higher GFAP expression (Fig. 6f). Knockdown of SOX2OT in CLP mice partially normalized these effects of CLP, although expression levels remained significantly different from those in sham animals.

\section{SOX2OT knockdown decreased hippocampal SOX2 and} OCT4 levels in mice with sepsis-associated encephalopathy

Western blot and RT-PCR assays showed that CLP mice expressed higher levels of SOX2 and OCT4 proteins (Fig. 7a, b) and transcripts (Fig. 7c) than sham mice. Treating CLP animals with SOX2OT siRNA 

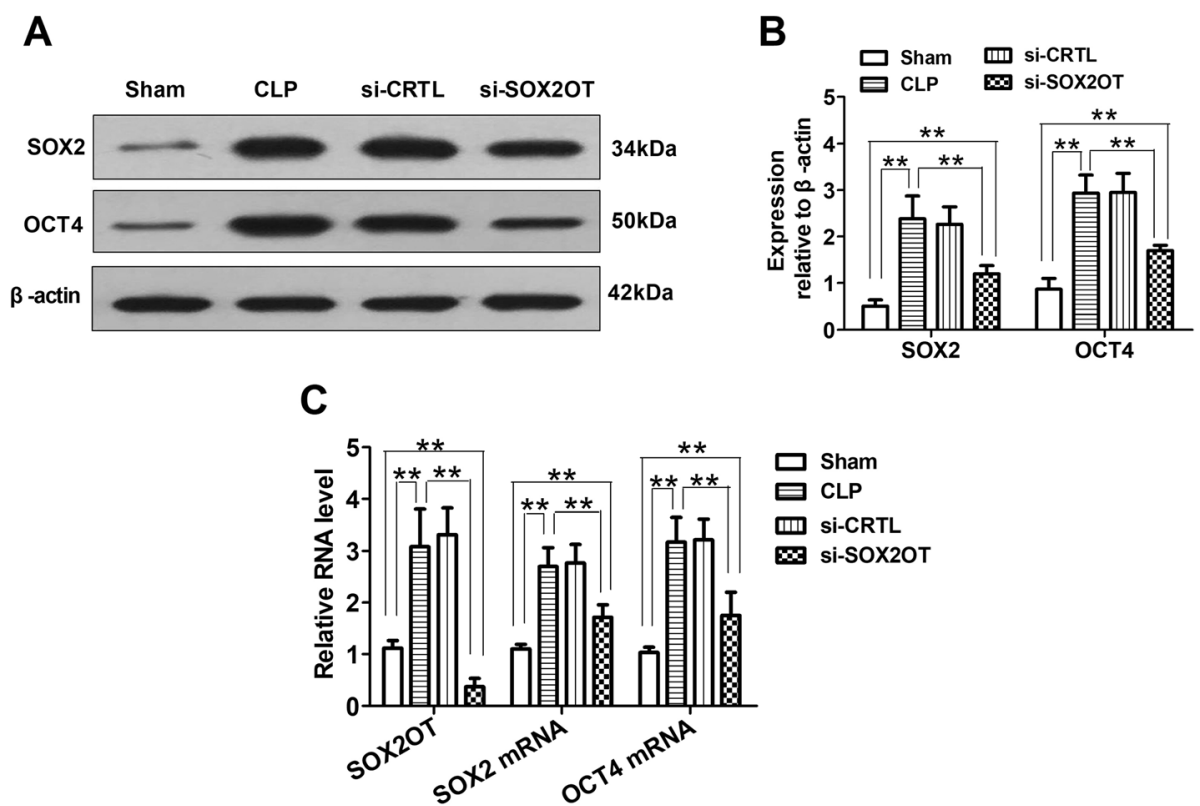

Fig. 7 SOX2OT knockdown downregulated SOX2 and OCT4 in the hippocampus of mice with sepsis-associated encephalopathy. a Representative images showing SOX2 and OCT4 protein bands in hippocampal tissue from CLP mice injected with SOX2OT siRNA or scrambled control. b Densitometry quantitation of SOX2 and OCT4 expression. $\beta$-actin was used as an internal control. c Levels of SOX2OT, SOX2, and OCT4 transcripts ( $n=8$ /group). ${ }^{* *} p<0.01$. Abbreviations: CLP, cecal ligation and perforation; si-CRTL, scrambled control siRNA; si-SOX2OT, SOX2OT siRNA

downregulated SOX2 and OCT4 at the protein and mRNA levels. No significant difference was detected between CLP mice transfected with scrambled siRNA and untransfected CLP mice.

SOX2 knockdown attenuated sepsis-induced cognitive dysfunction and changes in neuronal populations in mice with sepsis-associated encephalopathy

SOX2OT somehow acts via SOX2 to repress neural progenitor proliferation and promote neuronal differentiation in the developing mouse cerebral cortex [15]. After observing that SOX2OT knockdown in our CLP mice downregulated SOX2 in hippocampal tissue, we asked whether knocking down SOX2 directly would have the same effects as knocking down SOX2OT. In the Morris water maze, SOX2 siRNA decreased escape latency in CLP mice (Fig. 8a), while there was no difference in swimming speed among groups (Fig. 8b). Similarly, SOX2 siRNA-transfected mice spent more time in and had more crossings of the target quadrant than untransfected CLP mice (Fig. 8c, d). SOX2 knockdown led to longer freezing time (Fig. 8e, f). Likewise, SOX2 knockdown was associated with increased levels of proliferation (Ki67) and maturation markers (NeuN) and decreased levels of differentiation (GFAP) (Fig. 6), and reversed CLP-induced changes in hippocampal neurogenesis (Fig. 9).

\section{Discussion}

This study provides additional insights into the mechanisms behind cognitive deficits in sepsis-associated encephalopathy. First, our data demonstrated that sepsis induced by CLP surgery led to cognitive dysfunction and upregulation of SOX2OT and SOX2. Second, we found that SOX2OT knockdown inhibited downstream SOX2 expression and levels of neuronal markers in CLP mice, and reduced the number of cells positively stained for BrdU plus doublecortin and BrdU plus NeuN, except BrdU plus GFAP. Third, SOX2 knockdown produced similar effects as SOX2OT knockdown. Collectively, these data suggest that inhibiting the SOX2OT-SOX2 signaling axis can protect the hippocampus from sepsisinduced hippocampal neurogenesis deficits and neurodegeneration.

In this study, sepsis caused cognitive deficits that were detected as decreased time spent in the target quadrant in the Morris water maze test and shorter freezing time in a conditioned fear test. In addition, sepsis downregulated the expression of neuronal markers for stem cells (nestin and BLBP), proliferation (Ki67), and differentiation (DCX). Sepsis also led to higher levels of the astrocytic marker GFAP, indicating dysfunction differentiation of neurons in the hippocampal dentate gyrus. In many species, neural stem cells in the dentate gyrus of the adult hippocampus maintain the ability to generate self-renewing, multipotent neurons [6]. Direct 


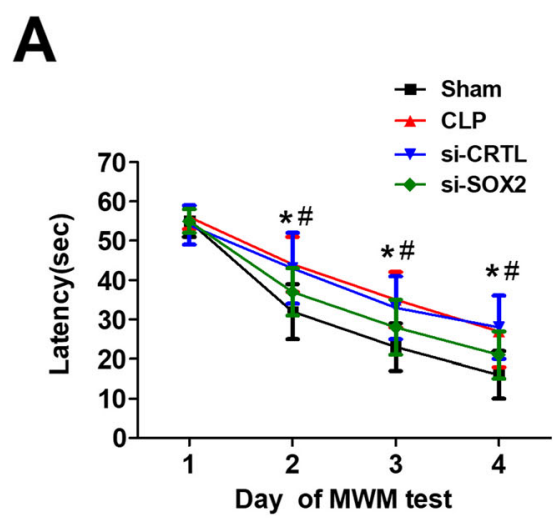

B

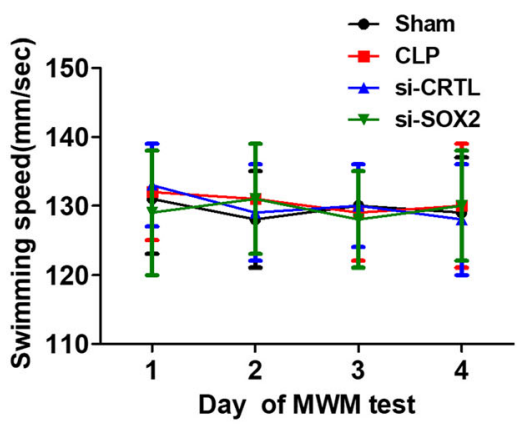

C

D
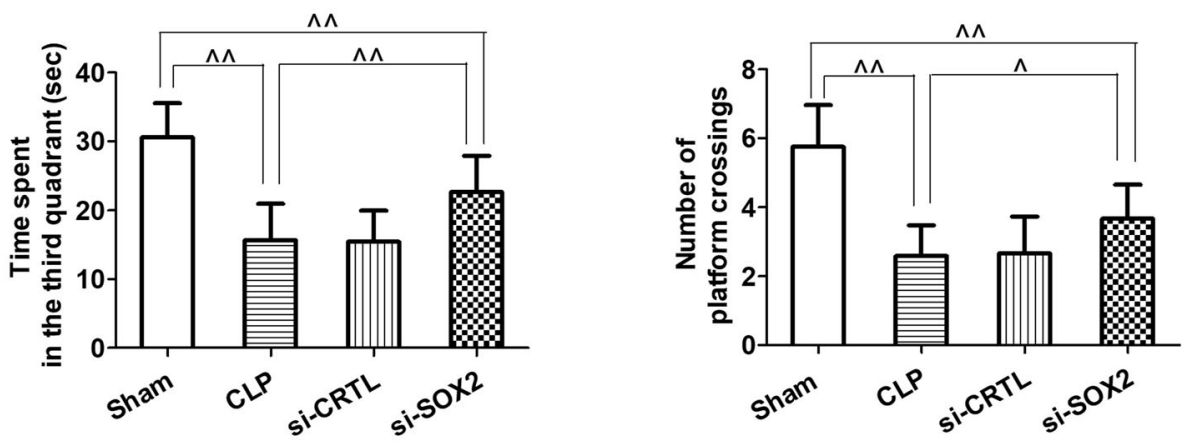

$\mathbf{E}$

$\mathbf{F}$
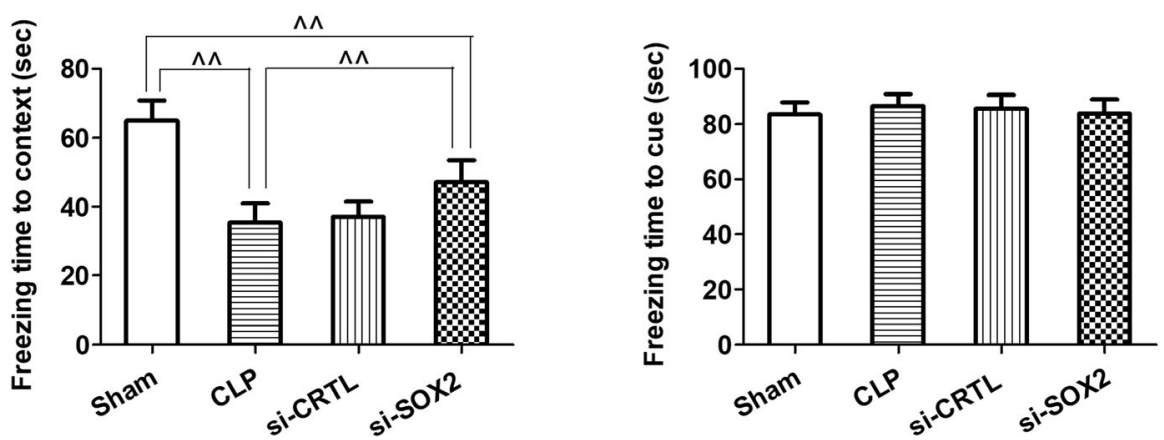

Fig. 8 SOX2 knockdown using siRNA alleviated sepsis-induced cognitive dysfunction in sepsis-associated encephalopathy mice. a Escape latency, b swimming speed, $\mathbf{c}$ time spent in the target quadrant, and $\mathbf{d}$ number of times mice crossed the target quadrant on the test day in the Morris water maze. e Freezing time to context and $\mathbf{f}$ freezing time to cue in the fear conditioning test ( $n=16 /$ group). ${ }^{\&} p<0.05$ vs. day 1 of Morris water maze test; ${ }^{*} p<0.05$ vs. Sham; ${ }^{p} p<0.05$ vs. CLP; $\wedge p<0.05 ; \wedge \wedge p<0.01$. Abbreviations: CLP, cecal ligation and perforation; si-CRTL, scrambled control siRNA; si-SOX2, SOX2 siRNA

or indirect stimulation of hippocampal neurogenesis, such as through exercise or consumption of green tea flavonoids, can enhance memory function and synaptic plasticity after neural stem cell differentiation $[4,7,21]$. However, aberrant proliferation and differentiation of adult neural stem cells or neuronal progenitor cells, induced by stress or pathological stimulation (e.g., through drugs, hormones, growth factors), can "derail" hippocampal neurogenesis, leading to deficits in cognitive functions including learning and memory [22-24]. For example, inducing sepsis in rats by CLP surgery disturbs adult neurogenesis in the subventricular zone [25]. Lipopolysaccharide-induced neuroinflammation in mice decreases immature and mature neuronal differentiation of neural stem cells and reduces neural stem cell proliferation and survival in adult hippocampal dentate gyrus 


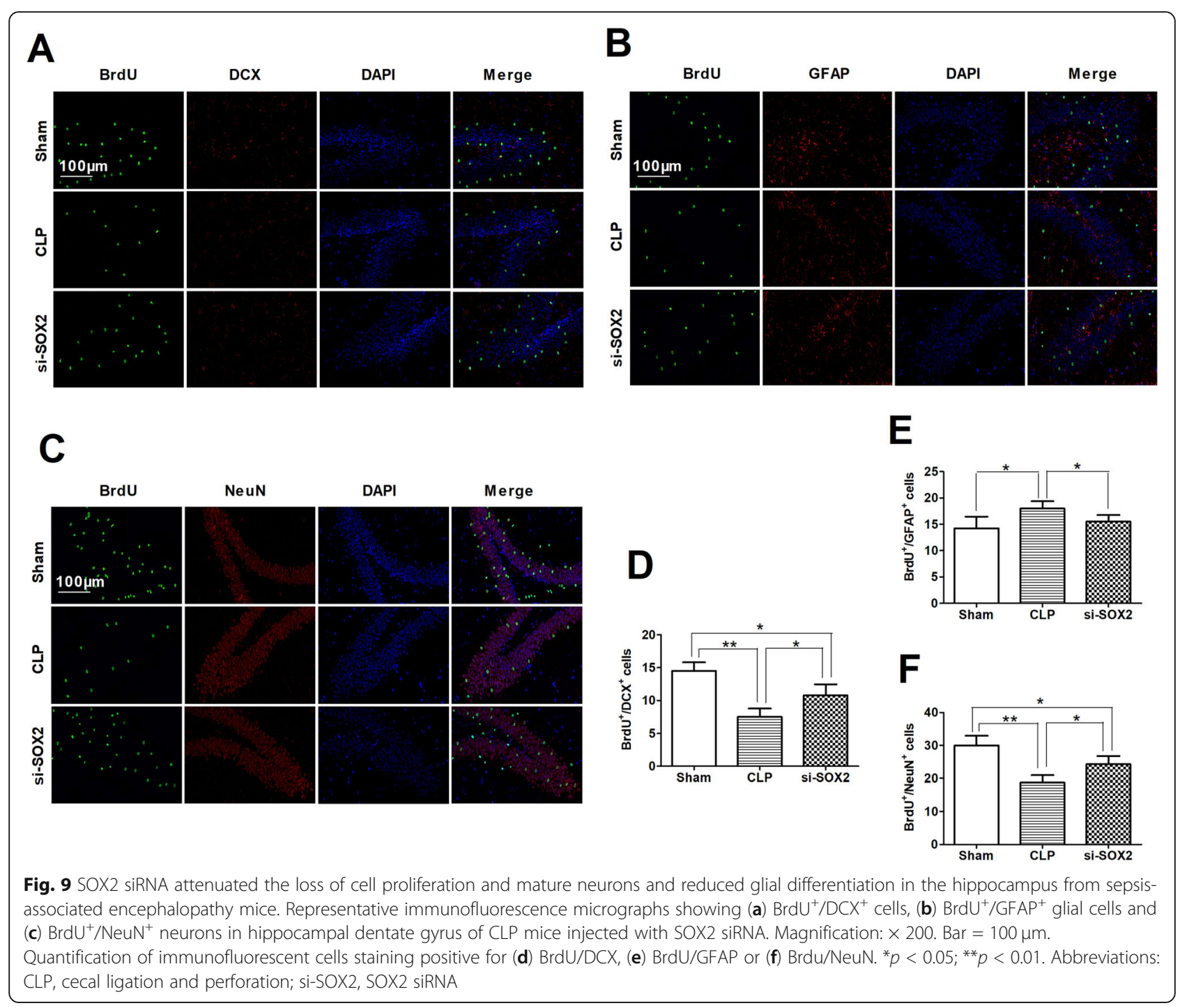

[26]. Therefore, we speculate that sepsis-induced decline in learning and memory in CLP mice may be triggered by deficits in hippocampal neurogenesis.

Various lncRNAs have been shown to determine neural fate and regulate neurogenesis [9, 27]. SOX2OT is expressed in the developing mouse cerebral cortex, predominantly in the nucleus, and it represses neural progenitor proliferation and promotes neuronal differentiation [15]. Experiments in vitro have shown that SOX2OT is upregulated in the early stages of neural stem cell differentiation and then is gradually downregulated as differentiation proceeds [12]. During early neurodevelopment in mice, SOX2OT may regulate stemness, cell proliferation, and differentiation into neurons or glia [28]. We found that sepsis activated SOX2OT in the hippocampus, and SOX2OT knockdown attenuated sepsis-induced deficits in hippocampal neurogenesis and cognitive function. These results are consistent with previous results connecting SOX2OT upregulation with cognitive impairment in Alzheimer's disease [13]. In addition, SOX2OT knockdown in adult mice can protect against hyperglycemia-induced retinal neurodegeneration [29].

Our results identified SOX2 as a downstream target of SOX2OT. Moreover, we found that SOX2 knockdown reduced sepsis-induced hippocampal neurogenesis and cognitive dysfunction, similar to the beneficial effects of SOX2OT knockdown. SOX2 is a transcription factor derived from a single exon within an intron of SOX2OT, and its coding sequence lies in the same transcriptional orientation as the IncRNA SOX2OT [12, 13]. SOX2 is uniformly expressed in neural stem cells and critical in the development, maintenance, and differentiation of hippocampal stem and progenitor cell populations [30-33]. Conditional ablation of SOX2 in adult neural progenitor cells impedes activation of pro-neural and neurogenic 
genes, resulting in increased neuroblast death and functionally aberrant newly derived neurons [34]. Our result is distinct from studies of SOX2 in the injured spinal cord injury [35], where it is found to show that resident astrocytes can be converted to DCX-positive neuroblasts by SOX2. Our results suggest that inhibition of the SOX2OT/SOX2 axis increases proliferation and survival of mature neurons, in a possible attempt to compensate for the devastating effect of sepsis and sepsis-associated encephalopathy on the brain.

Furthermore, our data suggest that sepsis upregulates the transcription factor OCT4 through the SOX2OT/ SOX2 axis. OCT4 is the most studied SOX2-binding partner, and its overexpression in SOX2-null mouse embryonic stem cells rescues their pluripotency [36, 37]. This implies that SOX2 is crucial for maintaining their pluripotency, possibly through promoting and maintaining OCT4 expression.

There were some limitations to this study. We only examined brain neurogenesis in hippocampal dentate gyrus since the focus was sepsis-induced cognitive deficits. Brain neurogenesis can also be found in the subventricular zone (SVZ), which is an important source of neuronal regeneration [23-25]. The effect of sepsis on neurogenesis in SVZ remains unknown, warranting further investigation.

\section{Conclusions}

In summary, in adult sepsis, the hippocampal SOX2OT are activated, resulting in deficits of hippocampal neurogenesis and cognitive function. SOX2OT knockdown attenuated sepsis-induced neurogenesis impairment and cognitive dysfunction, likely through its effects on downstream SOX2 signaling. We provide preliminary evidence that targeting SOX2OT/SOX2 axis may provide a therapeutic strategy for treating or preventing neurodegeneration in sepsis-associated encephalopathy.

\section{Abbreviations \\ BLBP: Brain lipid-binding protein; BrdU: Bromodeoxyuridine; CLP: Cecal ligation and perforation; DAPI: 4,6-Diamidino-2-phenylindole; DCX: Doublecortin; GFAP: Glial fibrillary acidic protein; IncRNA: Long noncoding RNA; NeuN: Neuronal nuclei; OCT4: Octamer-binding transcription factor 4; PBS: Phosphate-buffered saline; RT-qPCR: Reverse transcription-quantitative polymerase chain reaction; SDS-PAGE: Sodium dodecyl sulfate-polyacrylamide gel electrophoresis; siRNA: Short interfering RNA; SOX2: Sex-determining region Y-box 2; SOX2OT: SOX2 overlapping transcript; SPSS: Statistical Package for Social Sciences}

\section{Acknowledgements}

Not applicable.

\section{Authors' contributions}

Yanna Si and Jialin Yin conceived and designed the study. Yanan Shen performed the majority of the experiments. Jiayue Du assisted with tissue sample collection. Yanna Si and Yinjia Lin both wrote and edited the manuscript. Yuan Zhang and Yan Xing analyzed the data. Hongguang Bao and Xiajuan Hu helped edit the manuscript. All authors read and approved the final version of the manuscript.

\section{Funding}

This work was supported by the National Natural Science Foundation of China (81873954 and 81971872), Nanjing Medical Science and Technical Development Foundation (QRX17019 and YKK18105), and the Six Talent Peaks Project of Jiangsu (WSW-106).

\section{Availability of data and materials}

All data generated or analyzed during this study are available from the corresponding author upon request.

\section{Ethics approval and consent to participate}

No human data or tissues were used in this study. All animal experimental protocols and handling procedures were approved by the Institutional Animal Care and Use Committee at Nanjing Medical University.

Consent for publication

Not applicable.

\section{Competing interests}

The authors declare no conflicts of interest.

\section{Author details}

${ }^{1}$ Department of Anesthesiology, Nanjing First Hospital, Nanjing Medical University, Nanjing 210006, People's Republic of China. ${ }^{2}$ Mechanical Engineering, Southeast University, Nanjing 211118, People's Republic of China.

Received: 17 April 2020 Accepted: 28 September 2020

Published online: 25 October 2020

\section{References}

1. Yamaga S, Shime N, Sonneville R, de Montmollin E, Timsit JF. Risk factors for sepsis-associated encephalopathy. Intensive Care Med. 2017:43(10):1548-9.

2. Widmann CN, Heneka MT. Long-term cerebral consequences of sepsis. Lancet Neurol. 2014;13(6):630-6.

3. Sonneville R, de Montmollin E, Poujade J, Garrouste-Orgeas M, Souweine B, Darmon M, Mariotte E, Argaud L, Barbier F, Goldgran-Toledano D, Marcotte G, Dumenil AS, Jamali S, Lacave G, Ruckly S, Mourvillier B, Timsit JF. Potentially modifiable factors contributing to sepsis-associated encephalopathy. Intensive Care Med. 2017;43(8):1075-84

4. Seong KJ, Lee HG, Kook MS, Ko HM, Jung JY, Kim WJ. Epigallocatechin-3gallate rescues LPS-impaired adult hippocampal neurogenesis through suppressing the TLR4-NF-KB signaling pathway in mice. Korean J Physiol Pharmacol. 2016;20(1):41-51.

5. Kheirbek MA. Finding the roots of adult neurogenesis. Cell. 2015;161(7): $1500-2$

6. Ryan SM, Nolan YM. Neuroinflammation negatively affects adult hippocampal neurogenesis and cognition: can exercise compensate? Neurosci Biobehav Rev. 2016;61:121-31.

7. Littlefield AM, Setti SE, Priester C, Kohman RA. Voluntary exercise attenuates LPS-induced reductions in neurogenesis and increases microglia expression of a proneurogenic phenotype in aged mice. J Neuroinflammation. 2015;12: 138.

8. Chen L, Feng P, Zhu X, He S, Duan J, Zhou D. Long non-coding RNA Malat1 promotes neurite outgrowth through activation of ERK/MAPK signalling pathway in N2a cells. J Cell Mol Med. 2016;20(11):2102-10.

9. Song JS, Lim DA. Integration of genome-wide approaches identifies IncRNAs of adult neural stem cells and their progeny in vivo. Cell Stem Cell. 2013;12(5):616-28.

10. Ramos AD, Andersen RE, Liu SJ, Nowakowski TJ, Hong SJ, Gertz CC, Salinas $\mathrm{RD}$, Zarabi $H$, Kriegstein AR, Lim DA. The long noncoding RNA Pnky regulates neuronal differentiation of embryonic and postnatal neural stem cells. Cell Stem Cell. 2015;16(4):439-47.

11. Sun W, Pei L, Liang Z. mRNA and long non-coding RNA expression profiles in rats reveal inflammatory features in sepsis-associated encephalopathy Neurochem Res. 2017:42(11):3199-219.

12. Amaral PP, Neyt C, Wilkins SJ, Askarian-Amiri ME, Sunkin SM, Perkins AC, Mattick JS. Complex architecture and regulated expression of the SOX2OT locus during vertebrate development. RNA. 2009;15(11):2013-27.

13. Arisi I, D'Onofrio M, Brandi R, Felsani A, Capsoni S, Drovandi G, Felici G, Weitschek E, Bertolazzi P, Cattaneo A. Gene expression biomarkers in the 
brain of a mouse model for Alzheimer's disease: mining of microarray data by logic classification and feature selection. J Alzheimers Dis. 2011;24(4): $721-38$

14. Mercer TR, Dinger ME, Sunkin SM, Mehler MF, Mattick JS. Specific expression of long noncoding RNAs in the mouse brain. Proc Natl Acad Sci USA. 2008; 105(2):716-21.

15. Knauss JL, Miao N, Kim SN, Nie Y, Shi Y, Wu T, Pinto HB, Donohoe ME, Sun T. Long noncoding RNA SOX2OT and transcription factor YY1 co-regulate the differentiation of cortical neural progenitors by repressing Sox2. Cell Death Dis. 2018;9(8):799.

16. Bouglé A, Rocheteau P, Hivelin M, Haroche A, Briand D, Tremolada C, Mantz J, Chrétien F. Micro-fragmented fat injection reduces sepsis-induced acute inflammatory response in a mouse model. Br J Anaesth. 2018;121(6):1249-59.

17. Chen L, Dong R, Lu Y, Zhou Y, Li K, Zhang Z, Peng M. MicroRNA-146a protects against cognitive decline induced by surgical trauma by suppressing hippocampal neuroinflammation in mice. Brain Behav Immun. 2019;78:188-201

18. Ni J, Wang $X$, Chen $S$, Liu H, Wang Y, Xu X, Cheng J, Jia J, Zhen X. MicroRNA let-7c-5p protects against cerebral ischemia injury via mechanisms involving the inhibition of microglia activation. Brain Behav Immun. 2015;49:75-85.

19. Si $Y$, Zhang $Y$, Han $L$, Chen $L$, Xu Y, Sun F, Ji M, Yang J, Bao $H$. Dexmedetomidine acts via the JAK2/STAT3 pathway to attenuate isoflurane-induced neurocognitive deficits in senile mice. PLoS One. 2016; 11(10):e0164763.

20. Ji MH, Tang H, Luo D, Qiu LL, Jia M, Yuan HM, Feng SW, Yang JJ. Environmental conditions differentially affect neurobehavioral outcomes in a mouse model of sepsis-associated encephalopathy. Oncotarget. 2017; 8(47):82376-89.

21. Lledo PM, Alonso M, Grubb MS. Adult neurogenesis and functional plasticity in neuronal circuits. Nat Rev Neurosci. 2006;7(3):179-93.

22. Gonçalves JT, Schafer ST, Gage FH. Adult neurogenesis in the hippocampus: from stem cells to behavior. Cell. 2016;167(4):897-914.

23. Kriegstein A, Alvarez-Buylla A. The glial nature of embryonic and adult neural stem cells. Annu Rev Neurosci. 2009:32:149-84.

24. Drew $L$, Fusi $S$, Hen R. Adult neurogenesis in the mammalian hippocampus: why the dentate gyrus? Learn Mem. 2013;20(12):710-29.

25. Bakirci S, Kafa IM, Uysal M, Ayberk KM. Increased adult neurogenesis in the subventricular zone in a rat model of sepsis. Neurosci Lett. 2011:497(1):27-31.

26. Cai B, Seong KJ, Bae SW, Kook MS, Chun C, Lee JH, Choi WS, Jung JY, Kim WJ. Water-soluble arginyl-diosgenin analog attenuates hippocampal neurogenesis impairment through blocking microglial activation underlying NF-KB and JNK MAPK signaling in adult mice challenged by LPS. Mol Neurobiol. 2019;56(9):6218-38.

27. Knauss JL, Sun T. Regulatory mechanisms of long noncoding RNAs in vertebrate central nervous system development and function. Neuroscience. 2013;235:200-14.

28. Tosetti V, Sassone J, Ferri ALM, Taiana M, Bedini G, Nava S, Brenna G, Di Resta C, Pareyson D, Di Giulio AM, Carelli S, Parati EA, Gorio A. Transcriptional role of androgen receptor in the expression of long noncoding RNA SOX2 in neurogenesis. PLoS One. 2017;12(7):e0180579.

29. Li CP, Wang SH, Wang WQ, Song SG, Liu XM. Long noncoding RNA-SOX2OT knockdown alleviates diabetes mellitus-induced retinal ganglion cell (RGC) injury. Cell Mol Neurobiol. 2017;37(2):361-9.

30. Taranova OV, Magness ST, Fagan BM, Wu Y, Surzenko N, Hutton SR, Pevny LH. SOX2 is a dose-dependent regulator of retinal neural progenitor competence. Genes Dev. 2006;20(9):1187-202.

31. Mir S, Cai W, Andres DA. RIT1 GTPase regulates Sox2 transcriptional activity and hippocampal neurogenesis. J Biol Chem. 2017;292(6):2054-64.

32. Niu W, Zang T, Zou Y, Fang S, Smith DK, Bachoo R, Zhang CL. In vivo reprogramming of astrocytes to neuroblasts in the adult brain. Nat Cell Biol. 2013;15(10):1164-75.

33. Oosterveen T, Kurdija S, Ensterö M, Uhde CW, Bergsland M, Sandberg M, Sandberg R, Muhr J, Ericson J. SoxB1-driven transcriptional network underlies neural-specific interpretation of morphogen signals. Proc Natl Acad Sci USA. 2013;110(18):7330-5.

34. Cimadamore F, Amador-Arjona A, Chen C, Huang CT, Terskikh AV. SOX2LIN28/let-7 pathway regulates proliferation and neurogenesis in neural precursors. Proc Natl Acad Sci USA. 2013;110(32):E3017-26.

35. Su Z, Niu W, Liu ML, Zou Y, Zhang CL. In vivo conversion of astrocytes to neurons in the injured adult spinal cord. Nat Commun. 2014;5:3338.
36. Masui S, Nakatake Y, Toyooka Y, Shimosato D, Yagi R, Takahashi K, Okochi H, Okuda A, Matoba R, Sharov AA, Ko MS, Niwa H. Pluripotency governed by Sox2 via regulation of Oct3/4 expression in mouse embryonic stem cells. Nat Cell Biol. 2007:9(6):625-35.

37. Fong $H$, Hohenstein KA, Donovan PJ. Regulation of self-renewal and pluripotency by Sox2 in human embryonic stem cells. Stem Cells. 2008; 26(8):1931-8.

\section{Publisher's Note}

Springer Nature remains neutral with regard to jurisdictional claims in published maps and institutional affiliations.
Ready to submit your research? Choose BMC and benefit from:

- fast, convenient online submission

- thorough peer review by experienced researchers in your field

- rapid publication on acceptance

- support for research data, including large and complex data types

- gold Open Access which fosters wider collaboration and increased citations

- maximum visibility for your research: over $100 \mathrm{M}$ website views per year

At BMC, research is always in progress.

Learn more biomedcentral.com/submissions 